\title{
Erratum to: Empirical ground-motion models for point- and extended-source crustal earthquake scenarios in Europe and the Middle East
}

\author{
S. Akkar - M. A. Sandıkkaya · J. J. Bommer
}

Published online: 6 September 2013

C) Springer Science+Business Media Dordrecht 2013

\section{Erratum to: Bull Earthquake Eng DOI 10.1007/s10518-013-9461-4}

1. There is a mistake in Eq. (2) and it should read as given in the following line (i.e., the erroneous ' $+\mathrm{S}$ ' term should be deleted):

$$
\begin{aligned}
& \ln \left(Y_{R E F}\right) \\
& = \begin{cases}a_{1}+a_{2}\left(M_{w}-c_{1}\right)+a_{3}\left(8.5-M_{w}\right)^{2}+\left[a_{4}+a_{5}\left(M_{w}-c_{1}\right)\right] \ln \left(\sqrt{R^{2}+a_{6}^{2}}\right) \\
+a_{8} F_{N}+a_{9} F_{R} & \text { for } M_{w} \leq c_{1} \\
a_{1}+a_{7}\left(M_{w}-c_{1}\right)+a_{3}\left(8.5-M_{w}\right)^{2}+\left[a_{4}+a_{5}\left(M_{w}-c_{1}\right)\right] \ln \left(\sqrt{R^{2}+a_{6}^{2}}\right) \\
+a_{8} F_{N}+a_{9} F_{R} \quad \text { for } M_{w}>c_{1}\end{cases}
\end{aligned}
$$

This error was not included in the Excel and Matlab routines provided in the electronic supplement and those resources can be used with confidence.

2. The list of co-authors is changed in Akkar et al. (2013). The proper citation to this paper is given below.

\section{Reference}

Akkar S, Sandıkkaya MA, Şenyurt M, Azari SA, Ay BÖ, Traversa P, Douglas J, Cotton F, Luzi L, Hernandez B, Godey S (2013) Reference database for seismic ground-motion in Europe (RESORCE). Bull Earthq Eng. doi:10.1007/s10518-013-9506-8

The online version of the original article can be found under doi:10.1007/s10518-013-9461-4.

S. Akkar $(\varangle) \cdot$ M. A. Sandıkkaya

Department of Civil Engineering, Earthquake Engineering Research Center,

Middle East Technical University, K6 Building, 06800 Ankara, Turkey

e-mail: sakkar@metu.edu.tr

\section{J. J. Bommer}

Civil and Environmental Engineering, Imperial College London, London SW7 2AZ, UK 
Acknowledgments Our thanks to Dr Stephen Bourne (Shell International) and Professor Frank Scherbaum (University of Potsdam) for alerting us to the first error. 